\title{
Perspectives, implementability and measurability of ethical principles in management
}

\author{
Georg Sievers M.Sc..$^{*}$ \\ ${ }^{1}$ GMS Wangen, Säntisweg 10, 88239 Wangen, Germany
}

\begin{abstract}
Ethical behaviour in companies is built on principles, rules, values and resources. As integrative ethics, the macro level ensures a long-term and sustainable orientation of the company in the context of business ethics. The macro level ensures that the company can change its role from "expactant" to "creator" with regard to corporate ethics. The mezzo level prevents unethical behaviour in companies by offering them the opportunity to reflect on their own behaviour in the context of (government) guidelines. Finally, the micro level is considered essential. It creates the systemic preconditions for companies to be able to fulfil their ethical duties and take responsibility for their actions. Partnerships and networks play a central role in this context. Against this background, the existence of a regulatory framework, the measurement of ethical corporate behaviour with the help of standards and reporting, the existence of a sustainable corporate mission statement as well as the availability of necessary resources and the documentation of sustainable behaviour in the company can be derived from the literature as central success factors for the implementation of ethical standards in companies. These factors are compared by means of empirical research with a focus on the packaging industry in Germany, Switzerland and Austria so that the existence of a guiding regulatory framework in society and a sustainable corporate mission statement emerge as the final and particularly relevant characteristics for an ethically-sustainable company, the referencing of one's own behaviour to sustainability indices, the use of the same (in particular the Dow Jones Sustainability (DJSI) and the Financial Times Stock Exchange (FTSE4 Good) indices) in reporting, the reference to the Sustainable Development Goals (SDGs) in the formulation of the corporate objective and the use of voluntary standards in sustainability reporting.
\end{abstract}

\section{Introduction}

Attributes of ethical behaviour in business are built on principles, rules, values and resources. The concept of principles becomes relevant when ethical thinking takes hold in such a way that morality becomes contentious, i.e. when discussions about "right" and "wrong" as well as "good" and "evil" arise. In this context, a "morally right action" is understood to be a qualitatively "right" action, which can then also be described as "ethically correct" $[1,2]$.

Principles then ensure that it is possible to classify what is "right" or "wrong" or "good" or "bad". These principles are codified within the company within the framework of (corporate) mission statements and thus develop into rules or corporate values. The common support of cultural and ethical values should lead to increased integration of the individual, improved coordination of the most diverse areas of the company, increased motivation of all those involved and thus ideally also to an increase and improvement of the company's success $[1,3]$. Finally, resources are necessary for implementation, as only if these are available is it possible to maintain competitiveness and competitiveness in the company. Resources thus present themselves as a prerequisite and a basis for integrative ethics which can be understood as a union between ethics and business at the micro, mezzo and macro levels. The "macro level" comprises the state, the government and the legislator, the "mezzo level" comprises companies, organisations and institutions, and the "micro level" comprises the acting individuals in organisations. With regard to the "macro level", the institutions then show themselves either in the form of the

\footnotetext{
* Corresponding author: g.sievers@web.de
} 
separation of powers (legislature, executive, judiciary and controlling) as well as in political coinages (fiscal, tax, social, monetary and foreign trade policy). This separation into micro, mezzo and macro levels is also referred to in the literature as the "subject matter of business ethics approach" [4]. Business ethics is thus based on the three levels mentioned above, which can serve as a basis for establishing ethical structures in companies and thus aim to reduce gaps between corporate behaviour and the documentation of sustainable behaviour in companies [5]. In addition to taking into account the three levels in companies, this can also be done in particular through cooperation between companies and the state [6]. The "level approach" - as it is abbreviated - assumes that business ethics is reflected in three social dimensions in the company [4], all of which are equally relevant for the implementation of business ethics, whereby there is a high degree of freedom in the design of the three levels and interdependencies do not necessarily exist [6]. Accordingly, the three levels or dimensions provide for the offer of legal framework conditions, create the basis for private ownership, entrepreneurial freedom and fair competition at the macro level $[7,8]$ and at the same time prevent unethical behaviour through incentive and sanction structures [4].

Against this background, it is important to question how it can be possible to operationally develop the "level approach" in the corporate context in order to exist and be perceived as an ethically-sustainable company.

\section{The state of the problem in the literature}

The macro level ensures a long-term and sustainable orientation of the company in the context of business ethics. The macro level ensures that the company can change its role from "expactant" to "creator" with regard to corporate ethics [2].

The mezzo level prevents companies from behaving unethically by offering them the opportunity to reflect on their own behaviour in the context of (state) requirements. Finally, the micro level is considered essential. It creates the systemic preconditions for companies to be able to fulfil their ethical duties and take responsibility for their actions. Partnerships and networks play a central role in this context [4].

The literature is based on the following assumption: If companies take ethical considerations into account at the micro level, as measured by relevant sustainability indices and reporting standards for sustainability, they can have an "ethics-improving" effect at the mezzo level in cooperation with other companies, organisations and institutions, and positive effects of their behaviour are ultimately reflected at the macro level in the form of macroeconomic factors [4].

At the macro level, macroeconomic factors can be useful in recognising whether states, governments or legislative institutions are implementing an "integrative ethic" [9].

Thus, on the macro level, the company and the state are addressed as two of three institutions that can be described as "places of morality". Through virtues and the adherence to values and norms, moral behaviour can be demonstrated and ultimately result in ethical behaviour [10,11] which can be seen in concrete terms in the national economy in the offer of relevant products and services that meet sustainable criteria. At the mezzo level, relevant requirements in the organisational process of the company ensure that a company behaves "correctly" - in the sense of "ethically correct". The Sustainable Development Goals (SDGs) serve as guidelines in setting goals for companies and can be operationalised in (sustainability) reporting through relevant standards such as those of the Global Reporting Initiative (GRI), the OECD or the UN Global Compact [12]. Finally, at the micro level, the focus is on the question of which microeconomic factors should be taken into account for the integration of issues into the corporate context or by management. The "Environmental Social Governance" (ESG) standards or the requirements of the "German Sustainability Code" (DNK) for reporting can be mentioned here as examples. The "Environmental Social Governance" (ESG) concept is intended to ensure the protection of the environment, compliance with social standards and good and sustainable corporate governance [13]. Through corporate principles, behavioural guidelines and a so-called "Code of Conduct" as well as orientation towards a vision (goal), a mission (self-image) and an orientation towards action (values) in the company, the standards can then be guidelines for the actions of each individual and ensure a positive appreciation of the actions of those concerned which can be achieved through orientation towards or the use of relevant market indices. the use of relevant market indices such as the German Environmental Social Governance Index (DAX 50 ESG), the Dow Jones Sustainability Index (DJSI), the Financial Times Stock Exchange (FTSE4Good) and the STOXX SI Index [11].

Taking these levels into account and considering the interrelationships, it can ultimately be possible to positively accompany a change that is permanently present in the company and to address the needs of the various stakeholders equally [14]. Business ethics examines whether and to what extent moral standards can be integrated in corporate policy and in the behaviour of companies in order to finally achieve the application of a moral code of conduct to all economic levels within the framework of economic ethics [10]. The challenge for companies in the context of (alternative) ethical behaviour is to integrate the (necessary) self-interest or the pursuit of profit and the pursuit of ethical values in corporate policy which can be done by taking into account the "Golden Rule" - i.e. the reciprocity of human action - as well as the "Practical Syllogism" in the form of a concept of responsibility that can be understood as "ethical economics".[15] defines "ethical economics" as a "theory of the integration of economics and ethics". 
From this, the literature can define the "ethical minimum" in questions of accounting and in questions of corporate organisation from the perspective of the stakeholders as framework conditions that can be understood as the consideration of ethical requirements in the company to ensure economic and legal capacity to act [16]. Divided into the three levels of analysis, activities in fiscal, tax, social, monetary and foreign trade policy can be identified for the macro view, following $[16,17,18]$. For the mezzo view, requirements within the framework of a corporate culture or through laws, regulations and guidelines can be mentioned and, for the micro view, it applies that the individual or the company perceives different roles in the real economic world (e.g. as entrepreneur, politician, customer or owner) and shows ethically "correct" (sustainable) behaviour here. From the literature, the following aspects can be named as the first relevant success factors for the formulation, operationalisation and implementation of ethical standards: existence of a sustainable corporate mission statement, existence of entrepreneurial resources, existence of a guiding regulatory framework, documentation of sustainable behaviour in the company as well as behaviour analogous to and measurement of entrepreneurial behaviour on indices and with the help of reporting standards $[19,20]$.

\section{Research design}

On the basis of comprehensive literature research, the status quo can first be ascertained within the frame-work of research on the topic under investigation. This literature research and the literature analysis based on it are oriented towards the key words sustainability, corporate ethics, ethical minimum, reporting, corporate structure as well as reporting/standards and the corresponding English counterparts. Based on this, an empirical vali-dation of the findings from the literature research is carried out. An online survey with the aim of ascertaining success factors for the implementation of ethical standards is used to ascertain the mezzo level, an expert sur-vey in the form of guided expert interviews with the aim of supplementing, modifying and excluding success factors from the online survey and literature research is used to ascertain the micro level [21], and an analysis of business and sustainability reports with the aim of ascertaining relevant macroeconomic indicators in the context of ethics and sustainability is used to ascertain the macro level. As a result, an (overall) index is created from these three empirical approaches, i.e. success factors that are relevant for ethically-sustainable behaviour of a company are derived in comparison with the results from the literature research. The result is a model for an ethically responsible company and recommendations for action are derived for companies - depending on the actual situation of the company. The validation of the model or the derivation of the weighting of the factors is carried out with the help of a logistic regression of the categories (variables) and a "receiver operating characteristics curve" (ROC) analysis is used to determine the cut-off value in order to derive degrees of fulfilment between companies with the highest possible selectivity.

\section{Results of the research}

\subsection{Results of the online survey}

A total of 136 participants took part in the online survey and completed it, 258 participants were approached - this represents a response rate of 52.71 percent. 4 participants were contacted via LinkedIn, 51 via Facebook, 7 participants via XING and 1 participant via Twitter. 67.5 percent of the respondents said that the company they represent comes from Germany, 21.7 percent from Austria, 7.2 percent from Switzerland and 2.4 percent from France (indicating the company's headquarters). The majority of respondents (29.7 percent) are located at the level of "Chief Executive Officers" (CEOs). With regard to the Sustainable Development Goals (SDGs), there is a "high" use/awareness of the SDGs with a focus on "Clean Water and Sanitation" (46.34 percent), "Industry, Innovation and Infrastructure" (42.86 percent) and "Peace, Justice and Strong Institutions" (48.15 percent). In terms of the effectiveness of the standards with regard to the public (stakeholders, shareholders) as well as with regard to the internal impact (optimisation of sustainable processes and structures, offer of sustainable products and services), the respondents rate the standards differently with a maximum value of five. The best values are given to voluntary standards, the "Environmental Social Governance" (ESG) indicators and the standards of the "Organisation for Economic Co-Operation and Development" (OECD standards). With regard to the implementation of sustainable or ethical orientation in companies, these focus in their implementation on the areas of processes, products and management. The focus is on clearly defined and standardised processes with a focus on sustainable products and a commitment to sustainability on the part of the management [19].

\subsection{Results of the expert survey}

Within the framework of the expert interviews, 8 experts - including one group interview with 3 experts - were interviewed. The interview guide focused on the question of how integrative ethics can be realised in the company and how implementation can be positively accompanied in the company. Here, the focus was on indica-tors, 
reporting standards and macroeconomic indicators, e.g. in the form of key business figures. The experts come from the packaging/sustainability context and are active there in company management or as company advisors. As a result, the experts formulate guiding principles in the company which include a statement on the working conditions, the health burdens at the workplace, the working hours and questions about the heaviness of the work as relevant factors for an ethical or sustainable orientation in the company. In second place is the existence of a so-called "Code of Conduct" in the company, which contains corporate values (especially integrity, fairness, networking) and is the basis for a corporate philosophy. Finally, the use of standards in sustainability reporting (especially standards of the International Standards Organisation (ISO 26000) and the Global Re-porting Initiative (GRI)) is mentioned in third place, $\mathrm{CO} 2$ emissions) and focus on business parameters (social commitment expenditures, equity ratio, investment ratio, return on sales, fluctuation rate) as well as employee satisfaction), thus enabling the use of indices ("Deutscher Aktienindex" (DAX) and "Dow Jones Sustainability Index" (DJSI)) in reporting.

\subsection{Results of the analysis of the annual and sustainability reports}

The annual and sustainability reports as well as - if necessary - supplemented publications of the companies were analysed with regard to sustainability indices used/addressed, formulated goals for sustainable development in the company based on the "Sustainable Development Goals" (SDGs) and addressing sustainable standards in reporting. The reports of Covestro AG, BASF, Siemens AG, Krones AG, the Tetra Laval Group, Syntegon Technology (formerly Bosch Packaging), KHS GmbH - which belongs to the Salzgitter Group -, KUKA AG, Gerresheimer AG, Gurit AG, Lanxess AG, OMV AG and Semperit AG were examined. A "best-in-class approach" was chosen here with regard to the "top 10 companies" in the packaging sector (wood, paper, glass, metal, other). In a first step, the analysis shows that the majority of the companies refer to the Global Reporting Initiative (GRI) or the United Nations (UN) Global Compact in their reports. Sustainability indices are referenced comparatively little in the reports. A second step shows that only about half of the companies explicitly refer to the Sustainable Development Goals (SDGs) in their reports. These are then also reported with a view to the key figures offered. In some cases (e.g. Siemens AG), the companies do refer to these indicators, but there is no concrete statement on fulfilment. This is only described verbally. Only two of the researched companies (Gerresheimer AG and Gurit AG) do not refer to the targets.

\subsection{Consolidation of the results: basis for the overall index formation}

Building on the success factors identified up to this point, the following success factors can serve as a basis expanded by the findings from the analysis of the annual/sustainability reports (cf. Chapter 4.3 .3 ) - for the formation of the overall index in the stated order of priority: existence of a guiding regulatory framework in society, existence of a sustainable corporate mission statement ("Code of Conduct") as a manifestation of a corporate philosophy, referencing of one's own behaviour to sustainability indices ("Dow Jones Sustainability Index" (DJSI), "Financial Times Stock Exchange"(FTSE4 Good)-Index), reference to selected "Sustainable Development Goals" (SGDs) ("Clean Water and Sanitation", "Industry, Innovation and Infrastructure", "Peace, Justice and Strong Institutions") in the formulation of corporate goals, use of voluntary standards in reporting, existence of corporate resources, focus in implementation on the areas of processes, products and management as well as internal documentation of sustainable behaviour in the company.

\subsection{Logistic regression of variables and ROC analysis}

Finally, the weighting of the individual categories is derived with the help of a logistic regression of the variables. The aim is to make a distinction between companies that fulfil the requirements and those that do not. Based on this, a receiver operating characteristics curve (ROC) analysis is used to determine the cut-off value. The result is a model that shows how strongly the variables are expressed in the company. In other words: the higher the value of the validated values, the more the company fulfils the requirements for ethical-sustainable behaviour in the company. In this way, the probabilities can be read whether the company will show ethical-sustainable behaviour or not on the basis of the recorded values of the variables. The following variables were given a final weighting: existence of a guiding regulatory framework, existence of a sustainable corporate mission statement, referencing of own behaviour to sustainability indications, reference to the Sustainable Development Goals (SDGs) as a corporate goal, use of voluntary standards for (sustainability) reporting, existence of corporate resources, focus in implementation on the areas of processes/products/management and internal documentation of sustainable behaviour in the company.

\section{Research recommendations and discussion}




\subsection{Implications for theory}

It became clear in the course of the investigation that there is comprehensive research regarding ethical issues, ethical issues within companies and also issues relating to sustainability. There is however a lack of a consistent connection of these deliberations which goes beyond merely applying corporate ethics. Connection means here that companies are offered concrete recommendations for action - based on the starting point - in a manner that implementation can take place. Here this thesis can close a gap by (a) providing, through the link between for methodological approaches (literature research, online questionnaire, expert interviews, analysis of business/sustainability reports) a holistic approach to identify the relevant factors in a corporate context and (b) subjecting these variables to an assessment in practice/making this possible. In this regard the following applies:

- a consideration of the ethical and sustainable objectives in the company with regard to the company reputation appears sensible. However, it is not a matter of orienting measurement of fulfilment to the company indicators but to the relevant factors for success.

- ensuring a division of these factors for success as much as possible which requires a validation of the variables with the help of empirical research methods.

- the opportunities to transfer in a beneficial manner ethical values in the company are to be found fundamentally in taking on board these factors for success, in the conduct of management (top management) (role model function of top management), the integration of ethics management into the strategic management of a company and transparent actions on the part of staff, shareholders and stakeholders.

The key question in the course of this thesis was: How can, based on key ethical values, implementation of ethical principles be possible in commercial management? This question can be answered as follows: the existence of a company model which contains company objectives and company values provides the initial basis for the company activity but also for the successful application of ethical principles in management. Based on this the following variables can apply as factors for success in order to make possible the objective of implementation of ethical principles in management:

- the existence of a guiding framework of order

- conduct analogue and measurement of corporate behaviour using indices and with the help of reporting standards

- the existence of corporate resources

- documentation of sustainable conduct in the company

Regarding the guiding framework what is relevant is that the actions of organisations/companies or individuals in companies/organisations are frequently regarded as an end in itself and not as a necessary part of a comprehensive code of conduct. In this regard one has to ascertain that first of all each individual is responsible in terms of his abilities for the shaping and securing of his life and for the shaping of his immediate environment and therefore also for his conduct in an organisation. Ultimately one cannot, however, dispense with a code of conduct as this provides the framework for conduct which corresponds to company guidelines. The existence of this code of conduct is the precondition that the invisible hand of the market leads to maximum well-being for all those concerned and balance in markets. Only through values, norms and conventions which are formed, according to Smith, in markets/society, then manifesting themselves in a code of conduct will a framework of orientation be formed - which should be understood as a framework of order - for all actions of companies, organisations and individuals. Thus, an unjust distribution of goods is prevented and stable imbalances are excluded in the long term as expressed in the moral philosophy of Smith whose morality is based on values such as sympathy and the existence of a moral society. However, it is harder to go down this path if the number of those individuals affected is higher and society becomes an anonymous large society without neighbourhood warmth and this leads to a loss of subjective conduct security. As a consequence, the influences differ for each individual increasingly and societal conduct control fails.

In this manner a society can develop increasingly into a route towards slavery. Only through close communication with society can societal conflicts be resolved which brings with it again the necessity for values to exist which society despite all the anonymity which has arisen can still constitute a basis. Whether this has to be crowned with success however may be quite questionable because then economic policy would fundamentally be laying down the law and the division of power on the part of the state has to be questioned as a consequence and the extent to which large, anonymous societies make possible an influencing of individuals at all is debatable.

However, in the age of societal change and increasing intercultural opening of society these attempts to create a framework of values appear now appear insufficient. Aspects of alienisation which attach themselves to globalisation, digitalisation, individualisation etc. make for a framework of order which contains sanctions which then determines again the actions of the individual.

For the usage/assessment of conduct in companies using indices and the application of reporting standards one can state that these are to be understood as a means to an end/as a toolkit in order to make possible the operational implementation of standards in companies and ensure their realisation. 
The availability of resources is part of this as without these realisation is not possible. The same applies to the documentation of implementation as the corresponding monitoring structures can only take place through such documentation.

Building upon this the following hypothesis was devised: Fundamentally ethics and economy are a contradiction but a world without ethics is inconceivable and the pursuit of economic goals of efficiency and effectiveness will only be possible together with the pursuit of ethical objectives. As a justification for this the following can be listed:

- In the course of the literature research, it became clear that through the existence of a guiding framework of order in society and the corresponding implementation in companies through mission statements, visions, missions and values a culture can be created which not only makes possible ethically oriented company conduct but which even promotes it.

- The then implemented ethical - sustainable direction in the company promotes the corporate image and reputation and makes for a higher level of trust on the part of consumers.

- Thus, not only societal added value is to be recognised through ethically sustainable conduct in the company but consumers may also prefer such companies in their selection choices.

\subsection{Implications for corporate practice}

For corporate practice what applies to companies is that they should orient their actions to the factors of success $[22,23]:$

- the existence of a sustainable company mission statement,

- referencing their own conduct to sustainability indices (Dow Jones Sustainability Index, FTSE4GOOD Index, other index),

- reference to the SDGs as corporate objectives (Clean Water and Sanitation, Industry/Innovation and Infra-structure, Peace/Justice and Strong Institutions, other),

- the usage of voluntary standards for (sustainability) reporting (GRI, ISO26000, UN Global Compact),

- the existence of corporate resources,

- recognising which criteria are relevant for measuring sustainability and can thus be included in the assessment of rating agencies, for example, focusing in implementation on the areas processes, products and management and

- internal documentation of sustainable conduct in the company.

The more this occurs the more ethically sustainable conduct in the company is both perceived and realisable and the chain of actions assumed in the hypothesis will take place.

Based on a comprehensive literature research on ethical-sustainable behaviour in companies, a set of variables and indicators was derived by validating these findings with the help of empirical methods (online survey, expert survey, analysis of business and sustainability reports) which serve as a basis for corporate management. Signals are set which, when perceived and aligned with business policy, will enable the demand for ethics and sustainability to be realised in the company in a targeted manner. It has become apparent in the course of the study that this possibility cannot be regarded as given in the research presented in the literature to date. Although there are extensive considerations in the literature on ethics and sustainability in the corporate context and the combination of these into an integrative ethics is also being discussed there have been no approaches to date. However, there has been a lack of approaches that have derived concrete variables in order to submit maxims for action for companies. The formulation of recommendations for action is still open. In a next research step, the identified and weighted variables will be separated into the sectors "red", "yellow" and "green", which should represent the need for action for the companies. Differentiated recommendations for action are then derived.

\section{Conclusion}

Ethical conduct in companies is based on principles, rules, values and resources. The macro- level ensures in the form of integrative ethics long-term, sustainable direction for the company in the context of corporate ethics. In this manner the macro-level ensures that the company can change its role from expectant to creator with respect to corporate ethics. The mezzo-level prevents unethical conduct on the part of companies by providing the opportunity to reflect upon self-conduct in the context of (state) instructions. The micro-level applies ultimately as an essential level. It creates the systemic preconditions such that companies can meet their ethical obligations and take responsibility for their actions. Partnerships and networks play in this context a key role. Given this background from literature central success factors can be identified for the implementation of ethical standards in companies: the existence of a framework of order, measuring ethical - corporate conduct with the help of standards and through reporting, the existence of a sustainable company mission statement and the existence of the necessary 
resources and documentation of sustainable conduct in companies. These factors are replicated through empirical research with a focus on the packaging industry in Germany, Switzerland and Austria such that ultimately and in particular relevant features for sustainable, ethical companies the following are shown: the existing of a guiding framework in society, a sustainable company mission statement, referencing self-conduct to sustainability indices, the usage of the same in reporting, reference to the SDGs in the formulation of the objective of the company and the usage of voluntary standards in sustainability reporting. If then a company presents itself as relatively welldeveloped in its implementation, then it is a matter of communicating the successes in order to achieve further positive effects in terms of reputation and image and, in addition, to intensify the application of methods not yet exploited sufficiently intensively. However, should a company demonstrate a backlog in the implementation of ethical - sustainable standards then it is a matter of identifying through a comprehensive analysis of the current state the fundamental needs for action, to prioritise these and then to implement them.

\section{References}

1. E. Göbel. Unternehmenspolitik - Grundlagen und praktische Umsetzung, 3rd edition, Konstanz: UVK (2003).

2. D. Smrekova. Morals, ethics and applied ethics. Filozofia, 52, 149-160 (1997).

3. S. Ozen. Ethic, the Theory of Ethics, the Ethics of Science, and Work, 8131-148 (2015).

4. A. Remišová, A. Lašáková. Unethical practices in the Slovak business environment - Entrepreneurs vs. State? Ethics \& Bioethics in Central Europe, 10, 78-95 (2020).

5. J.L. Fernández, J. Camacho. Effective elements to establish an ethical infrastructure - An exploratory study of SMEs in Madrid region. Journal of Business Ethics, 138, 113-131 (2016).

6. K.E. Goodpaster. Business Ethics. In: Becker, L./Becker, C. (Ed.), Encyclopedia of Ethics. New York: Garland, 111-115 (1992).

7. P. Ulrich. Integrative Wirtschaftsethik - Grundlagen einer lebensdienlichen Ökonomie. Berlin/Stuttgart/Wien: Haupt (1997).

8. E. Beauchemin, L.P. Cote, M-J. Drolet. Conceptualising Issues in the Conduct of Research - Results form a Critical and Systemic Literature Review. Journal of Academic Ethics, 4, 20201 (2021).

9. J.A. Marceta. Respect the Author - a Research Ethical Principle for Readers, Journal of Academic Ethics, 19, 175-185 (2021).

10. M.G. Velasquez. Business Ethics - Concept and Cases, 6th edition, New York: Prentice Hall (2005).

11. C. Nietsch-Hach. Ethisches Verhalten in der modernen Wirtschaftswelt, 2nd edition, Konstanz: UVK (2016).

12. D. Brockhoff, G. Engelhardt, H. Yabroudi, L. Karg, A. Aschenbrenner, C. Felber. Publizitätspflicht zur Nachhaltigkeit - Entwicklung eines Anforderungskataloges für einen universellen Standard (PuNa-Studie), Potsdam: Institute für Advanced Sustainability Studies (IASS) (2020).

13. F. Knecht, S. Reich. Wertschöpfungsketten - ESG als kritischer Erfolgsfaktoren für das Management des gesamten Lebenszyklus. In: S. Bergius/T. Schulz (Hrsg.), CSR und Finance - Beitrag und Rolle des CFO für eine Nachhaltige Unternehmensführung. Berlin/Heidelberg: Springer, 373-389 (2014)

14. U.P. Kanning, T. Staufenbiel. Organisationspsychologie. Göttingen: Hogrefe (2012)

15. P. Koslowski. Ethik der Banken. München: Fink, (2009).

16. L.K. Trevino, K.A. Nelson. Managing Business Ethics - Straight Talk About How To Do It Right, 5th edition, London: John Wiley \& Sons (2010).

17. S.O. Hansson. How to Perform an Ethical Risk Analysis (eRA), Risk Analysis - An International Journal, 38 , 1820-1829 (2018).

18. R.R. Kline. Engineering Case Studies - Bridging Micro and Macro Ethics, IEEE Technology and Society Magazine, 29, 16-19 (2010).

19. . Van der Wal, M.A. Demircioglu. More ethical, more innovative? The effects of ethical culture and ethical leadership on realized innovation. Australian Journal of Public Administration, 79, 386-404 (2020).

20. S.O. Hansson. The Ethics of Doing Ethics. Science and Engineering Ethics, 23, 105-120 (2017).

21. S. Thompson. The Micro-Ethics of Everyday Life Ethics. Cultural Studies, 26, 895-921 (2012).

22. C. Mackenzie. Ethical auditing and ethical knowledge. Journal of Business Ethics, 17, 1395-1402 (1998).

23. M. Ashby. Ethical Regulators and Super-Ethical Systems, Preprint, 8 (2020). 